\title{
High efficacy of alectinib in a patient with advanced lung adenocarcinoma with 2 rare ALK fusion sites: a case report
}

\author{
Yan Li ${ }^{1}$, Peng Duan ${ }^{2}$, Yan Guan ${ }^{1}$, Qing Chen $^{1}$, Anna Grenda ${ }^{3}$, Petros Christopoulos ${ }^{4}$, Marc G. Denis ${ }^{5}$, \\ Qisen Guo
}

${ }^{1}$ Department of Medical Oncology, Shandong Cancer Hospital and Institute, Shandong First Medical University \& Shandong Academy of Medical Sciences, Jinan, China; ${ }^{2}$ Department of Oncology, The Third People's Hospital of Qingdao, Qingdao, China; ${ }^{3}$ Department of Pneumonology, Oncology and Allergology, Medical University of Lublin, Lublin, Poland; ${ }^{4}$ Department of Thoracic Oncology, Thoraxklinik at Heidelberg University Hospital, Heidelberg, Germany; ${ }^{5}$ Nantes Université, CHU Nantes, Laboratoire de Biochimie, Nantes, France

Correspondence to: Qisen Guo. Department of Medical Oncology, Shandong Cancer Hospital and Institute, Shandong First Medical University \& Shandong Academy of Medical Sciences, Jinan 250117, China. Email: guoqs369@163.com.

\begin{abstract}
Anaplastic lymphoma kinase $(A L K)$ fusions have been identified in approximately $5 \%$ of nonsmall cell lung cancer (NSCLC) cases. ALK-tyrosine kinase inhibitors (TKIs) are the standard firstline treatment for patients with $A L K$-positive $(A L K+)$ advanced NSCLC. Along with widespread use of next-generation sequencing (NGS) for the molecular diagnosis of lung cancer, an increasing number of $A L K$ fusion partners are being reported, with the majority being effective for ALK-TKIs. Here, we present the case of a 42 -year-old female with no smoking history who was diagnosed with stage IVB lung adenocarcinoma. Two rare $A L K$ fusions were detected simultaneously by NGS in this patient: latent transforming growth factor beta-binding protein 1 (LTBP1)-ALK and huntingtin-interacting protein 1 (HIP1)-ALK. HIP1-ALK fusion was also detected by further RNA sequencing, but LTBP1-ALK failed to give a positive signal. The patient received alectinib as first-line therapy and consequently achieved a good response. Progression-free survival (PFS) was more than 19 months, and the treatment with alectinib is ongoing currently. During treatment, clinical symptoms disappeared and no significant adverse events occurred. This is the first case report describing a patient with an NSCLC tumor harboring 2 rare $A L K$ fusions who responded to alectinib. Our report enriches the knowledge of $A L K$ fusion sites and provides an effective clinical basis for the screening of sensitive fusions.
\end{abstract}

Keywords: Novel fusions; anaplastic lymphoma kinase ( $A L K)$; alectinib; lung adenocarcinoma; case report

Submitted Oct 13, 2021. Accepted for publication Jan 21, 2022.

doi: 10.21037/tlcr-21-1039

View this article at: https://dx.doi.org/10.21037/tlcr-21-1039

\section{Introduction}

Anaplastic lymphoma kinase $(A L K)$ gene rearrangement, a driver gene alteration underlying the carcinogenesis of non-small cell lung cancer (NSCLC), has been identified in approximately $5 \%$ of patients with advanced NSCLC (1-3). The $A L K$ gene, located on the short arm of chromosome 2 (locus 2p23), encodes for the ALK protein. ALK is a transmembrane receptor tyrosine kinase which consists of an extracellular ligand-binding domain, a transmembrane segment, a transmembrane domain, and an intracellular tyrosine kinase domain (4-6). $A L K$ was originally identified in anaplastic large-cell lymphoma (ALCL) in 1994 as NPM$A L K$ fusion (7). In 2007, Soda et al. first identified $A L K$ rearrangement in NSCLC, with the most common fusion being echinoderm microtubule-associated protein-like 4 (EML4)-ALK (8-11). Subsequent studies in mice showed this type of gene fusion to be strongly carcinogenic. Prior to the introduction of ALK inhibitors, patients with ELM4$A L K$ had a poor prognosis. The oncogenic activity of $E M L 4-A L K$ mainly depends on the fused protein of EML4 and $A L K$, which activates tyrosine kinase and thus multiple downstream signaling pathways, leading to the abnormal 
proliferation and inhibited apoptosis of tumor cells. ALK inhibitors impede the proliferation of tumor cells by binding to the tyrosine kinase domain located at the intracellular domain of the ALK protein and inhibiting the kinase activity of EML4-ALK fusion protein. Similar to EML4$A L K$, most rare $A L K$ rearrangements occur between a $5^{\prime}$ fusion partner and the 3' part of the $A L K$ gene encoding the kinase domain, creating an oncogenic $A L K$ tyrosine kinase that activates multiple downstream known cancer signaling pathways, including the phosphoinositide 3-kinase (PI3K)AKT, CRKL-C3G pathway, mitogen-activated protein kinase/ERK kinase (MEKK)2/3-mitogen-activated protein kinase/ERK (MEK)5-extracellular signal-regulated kinase 5 (ERK5) pathway, Janus kinase (JAK)/signal transducer and activator of transcription (STAT) pathway, and mitogenactivated protein kinase (MAPK) pathway, resulting in increased cell proliferation and survival $(12,13)$.

Since the discovery of EML4-ALK in NSCLC, a number of ALK tyrosine kinase inhibitors (TKIs) have been developed to treat $A L K$-positive $(A L K+)$ NSCLC. Rapid progress in the use of targeted therapies has led to significant improvements in progression-free survival (PFS) and overall survival (OS) in patients with metastatic $A L K$ rearranged NSCLC. Thus far, 6 ALK-TKIs have been approved for routine clinical use, including crizotinib, ceritinib, alectinib, brigatinib, ensartinib, and lorlatinib. The selective ALK-TKI, alectinib is recommended as the preferred first-line therapy option for patients with $A L K+$ metastatic NSCLC, as it has shown excellent PFS and OS, is supported by clinical trial data, and has been approved by the US Food and Drug Administration (FDA) (14-16). These trials also demonstrated that alectinib significantly improved central nervous system (CNS) efficacy versus chemotherapy or crizotinib.

Concurrently, the methods for detecting those with $A L K+$ NSCLC have shifted from traditional immunochemistry (IHC) and fluoresce in situ hybridization (FISH) to the more modern next-generation sequencing (NGS). Along with the widespread use of NGS in molecular diagnosis of lung cancer, a greater number of novel partner genes have been described, although $E M L 4-A L K$ remains the major fusion variant in $A L K+$ NSCLC, accounting for about 95\% of $A L K$ fusion variants in $A L K+$ NSCLC (17). Thus far, more than 92 distinct $A L K$ fusion partners (including noncoding RNAs) have been identified in NSCLC (18), most of which are effective against ALK-TKIs. It found that the most fusion site is located at exon 20 of $A L K$ gene.

This is the first reported case of a concurrent combination of two rare $A L K$ fusions that showed a favorable response to alectinib. Our report enriches the knowledge of $A L K$ fusion types and broadens the clinical basis for the screening and mechanistic workup of sensitive variants. We present the following article in accordance with the CARE reporting checklist (available at https://tlcr. amegroups.com/article/view/10.21037/tlcr-21-1039/rc).

\section{Case presentation}

A 42-year-old Chinese woman was admitted to Shandong Cancer Hospital and Institute for an irritating cough and shortness of breath which had persisted for about 2 months. The patient had been healthy in the past, and she had no history of smoking or family history of cancer. A contrastenhanced computed tomography (CT) scan (March 10, 2020) showed a $6.7 \mathrm{~cm} \times 5.4 \mathrm{~cm}$ mass in the right lower lobe and multiple masses with varying size in the brain. No bone metastases were identified by radionuclide bone scanning (figures not shown). A biopsy specimen was obtained by CT-guided lung biopsy. The cell morphology was consistent with lung adenocarcinoma (Figure 1A), and the tumor cells were positive for thyroid transcription factor-1 (TTF-1) and cytokeratin (CK)7, and negative for CK5 (Figure 1B). After comprehensive evaluation, the patient was diagnosed with metastatic lung adenocarcinoma (cT4N2M1c, stage IVB).

In order to clarify the genetic alterations of the tumor, we performed NGS on DNA isolated from the formalinfixed paraffin-embedded (FFPE) tissue acquired from the primary tumor biopsy. Based on a 456-gene panel (Berry Oncology Corporation, Fujian, China), DNA sequencing results identified 2 novel $A L K$ fusions sites: huntingtininteracting protein 1 (HIP1)-ALK (allelic frequency: 9.38\%) (Figure 2) and latent transforming growth factor betabinding protein 1 (LTBP1)-ALK (allelic frequency: 10.28\%) (Figure 3). Further IHC, using the D5F3 antibody (Ventana Medical Systems, Tucson, AZ, USA; Figure $4 A$ ) and FISH (Figure $4 B$ ) for $A L K$ were both strongly positive. The positive expression of $A L K$ in IHC and the FISH results suggested that the $A L K$ fusion was expressed at the protein level, indicating a carcinogenic mutation present in this patient. To further confirm this result and explore the exact fusion pattern, an RNA fusion panel based on amplicon sequencing was designed to identify the fusion variation (Berry Oncology). The NGS detection on RNA confirmed the HIP1-ALK fusion, but failed for LTBP1-ALK. Fusion results were validated using reverse transcriptase polymerase chain reaction (RT-PCR) and Sanger sequencing. 
A
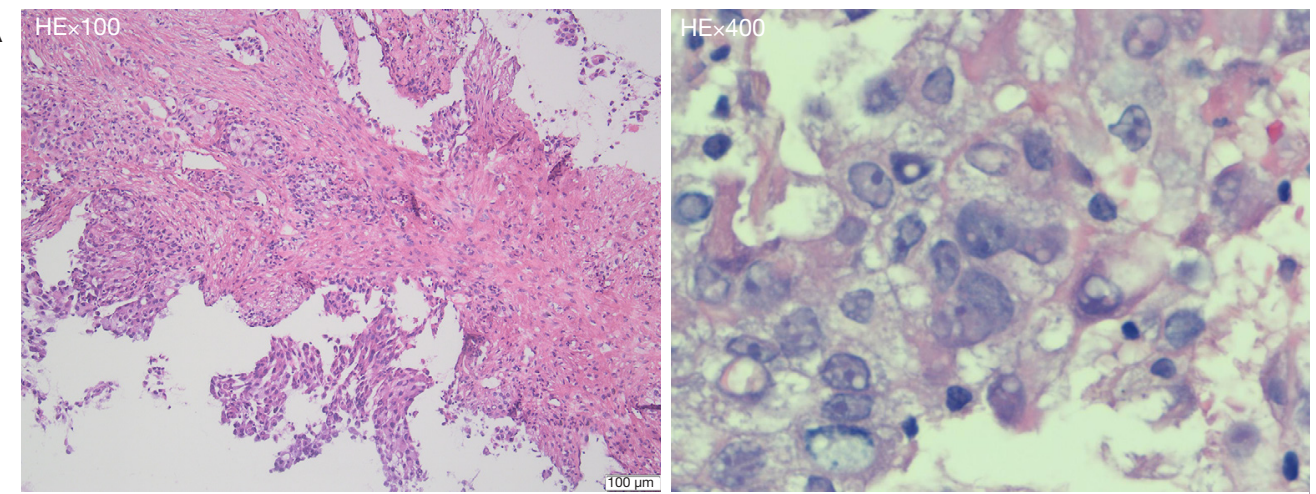

B
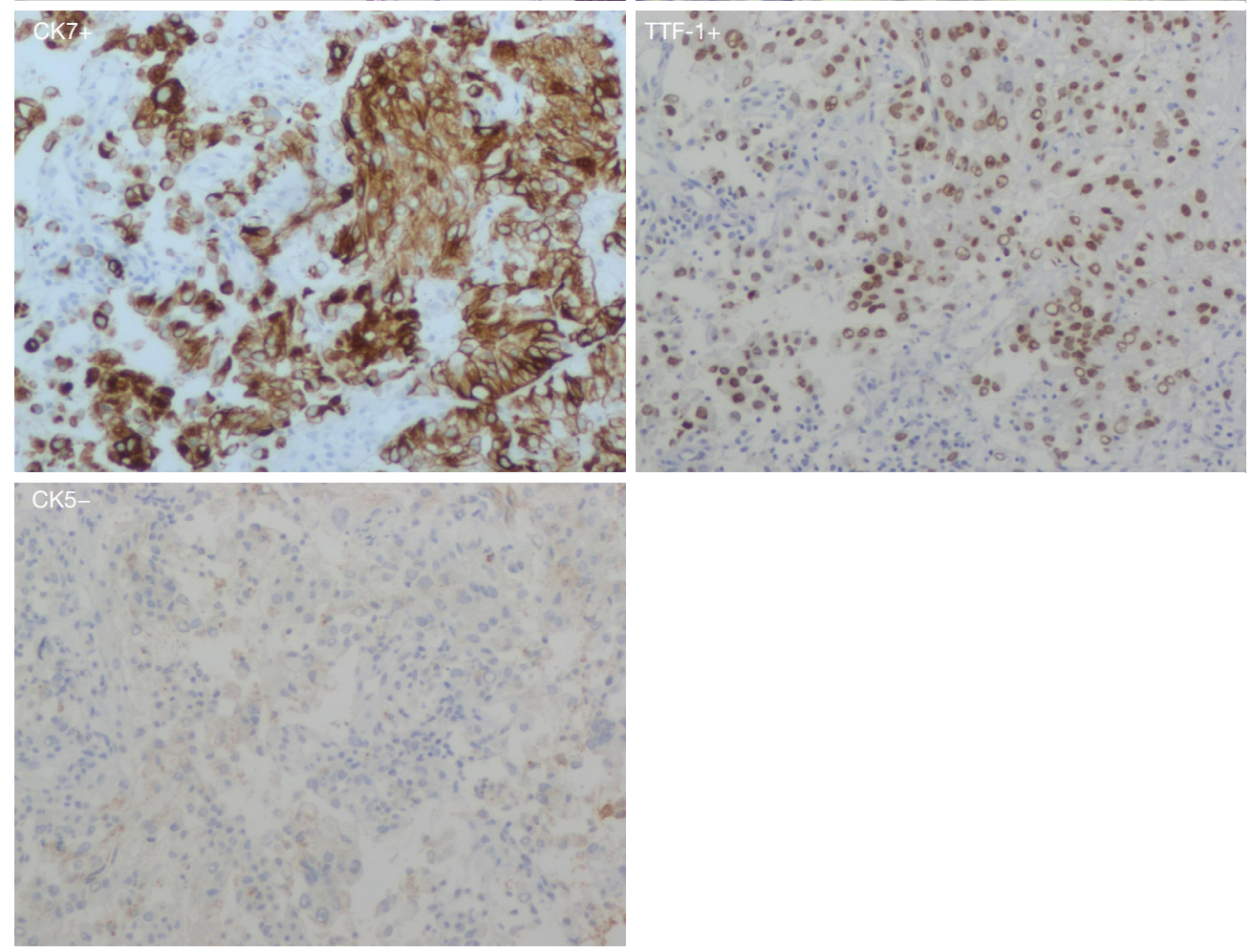

Figure 1 Histological findings from biopsy specimens. (A) Hematoxylin and eosin (HE) staining of tumor tissue (100x, 400×) showed lung adenocarcinoma; (B) immunohistochemistry (IHC) analysis of tumor tissue showed it was positive for thyroid transcription factor-1 (TTF-1) $(100 \times)$ and cytokeratin (CK)7 (100x), and negative for CK5 (100x).

The sequence analysis of $H I P 1-A L K \mathrm{cDNA}$ showed that exon 30 of HIP 1 was fused to exon 20 of $A L K$ in-frame, generating a fusion messenger RNA (mRNA) harboring an intact 5,415-base pair open reading frame encoding a deduced 1,805-amino acid protein sequence that contained epsin $\mathrm{N}$-terminal homology, coiled-coil, C-terminal homology, juxtamembrane, and kinase domains (Figures 2,5). The sequence analysis of $L T B P 1-A L K \mathrm{cDNA}$ showed that exon 3 of $L T B P 1$ was fused to exon 19 of $A L K$ in-frame (Figure 3).
The patient was treated with alectinib $(600 \mathrm{mg}$ twice per day) as first-line therapy as soon as the $L T B P 1-A L K$ and HIP1-ALK fusions were identified (March 31, 2020). After 1 month of therapy, the patient achieved complete remission of the clinical symptoms, including cough and shortness of breath, with no obvious adverse reaction other than mild constipation. CT scan images (April 27, 2020) revealed a significant response in the target lesion of the right lower lobe, which had obviously shrunk $(4.0 \mathrm{~cm} \times 3.0 \mathrm{~cm})$, while the brain lesions had nearly disappeared. The patient 

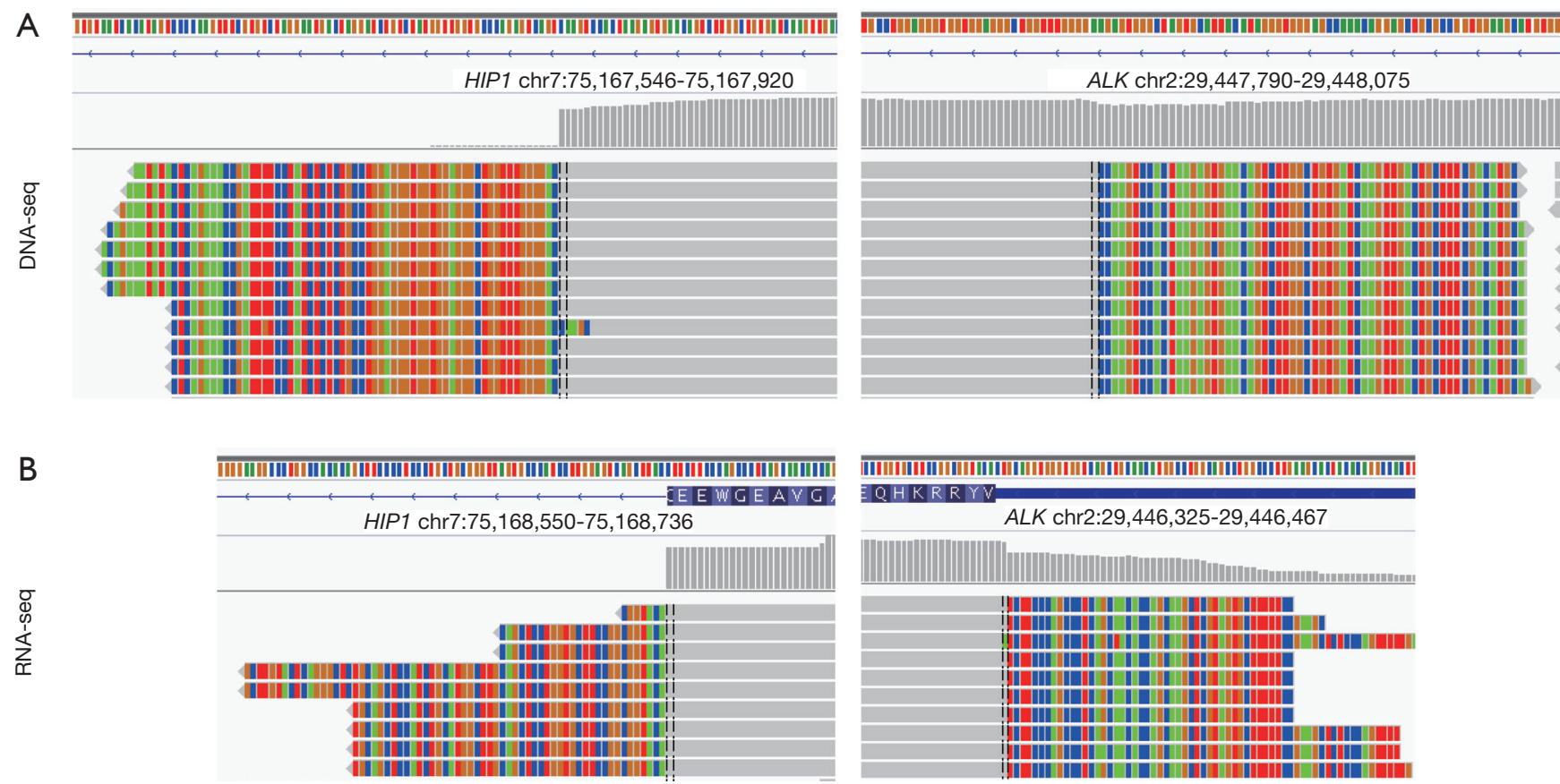

C

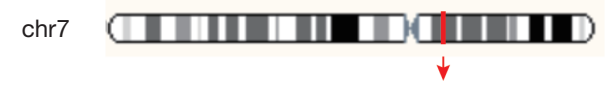

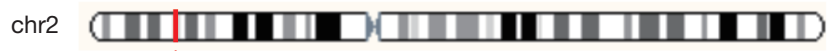
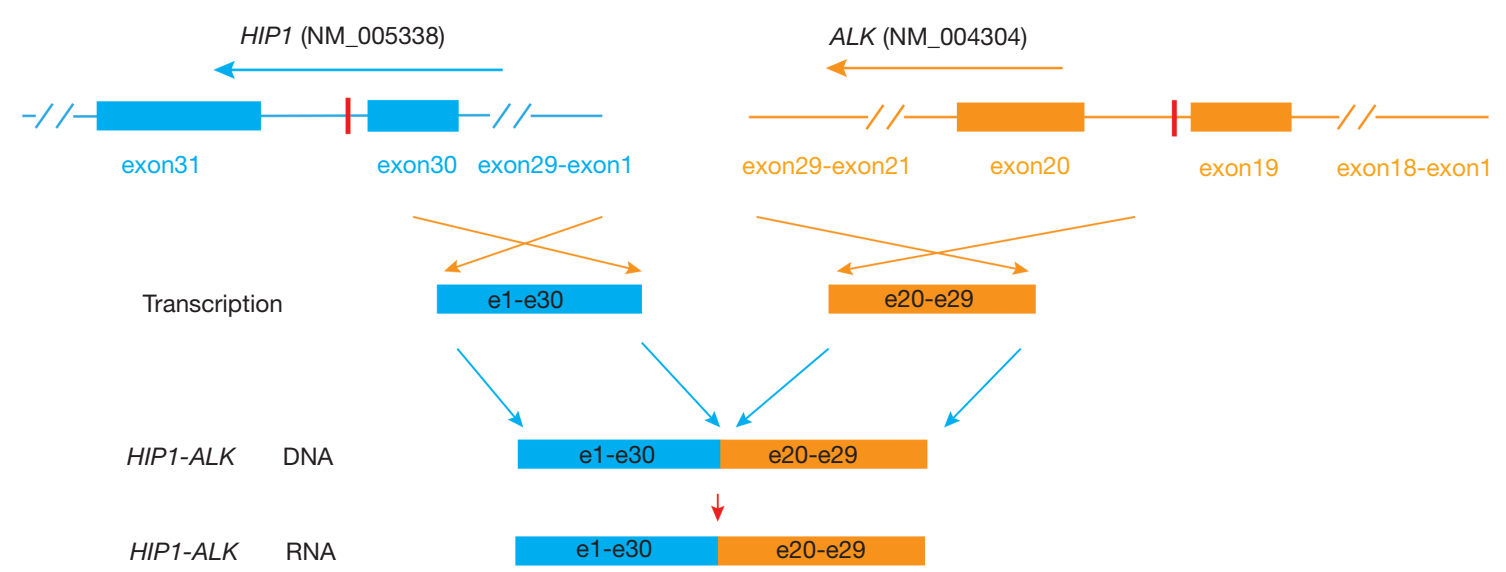

Figure 2 Identification and validation of the huntingtin-interacting protein 1 (HIP1)-anaplastic lymphoma kinase (ALK) fusion in a NSCLC patient. (A) DNA sequencing reads of HIP1 and $A L K$ were visualized by the Integrative Genomics Viewer (IGV); (B) RNA sequencing reads of HIP1 and $A L K$ were visualized by the Integrative Genomics Viewer (IGV); (C) a schematic map showing the structure of the HIP1-ALK fusion locus. NSCLC, non-small cell lung cancer.

achieved partial response (PR) according to the Response Evaluation Criteria in Solid Tumors, version 1.1 (RECIST 1.1) and until the last follow-up (November 03, 2021), the notable response was maintained (Figure 6). At the data cutoff (November 03, 2021), the patient remained on alectinib treatment, which had yielded a PFS of more than 19 months. As of this writing, alectinib treatment is ongoing. We will follow this patient and explore the mechanisms of alectinib resistance should disease recurrence or progress occur.

All procedures performed in this study were in accordance with the ethical standards of the institutional and/or national research committee(s) and with the Helsinki Declaration (as revised in 2013). Written informed consent was obtained from the patient for publication of this case report and accompanying images. A copy of the written 


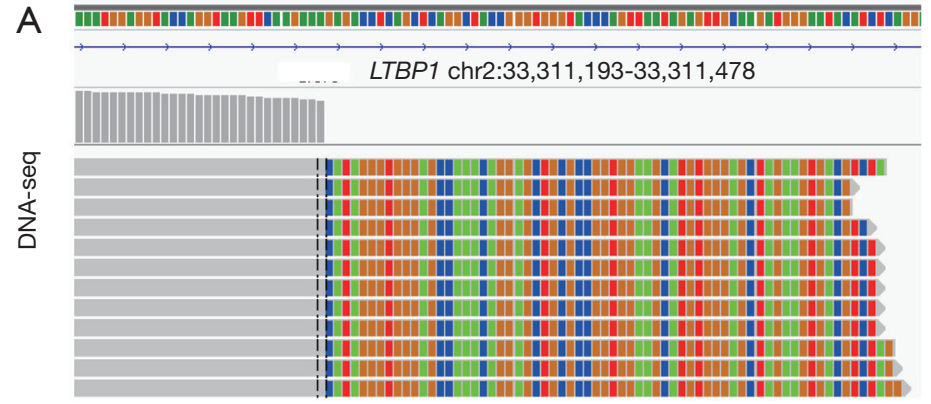

B

\begin{abstract}
chr2
\end{abstract}
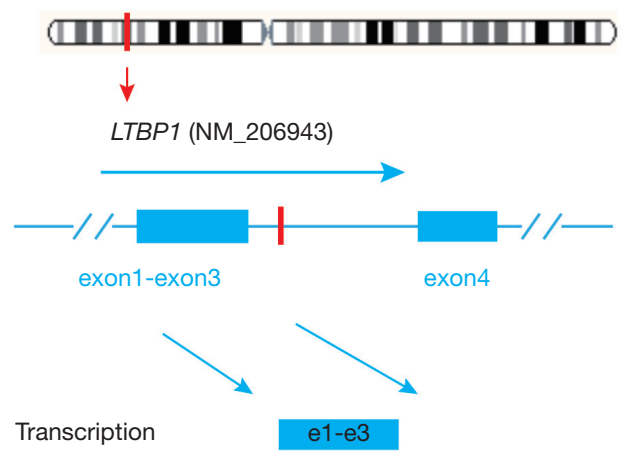

Transcription
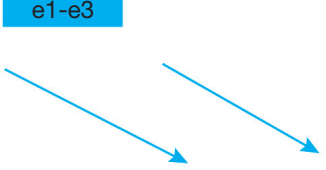

LTBP1-ALK mRNA

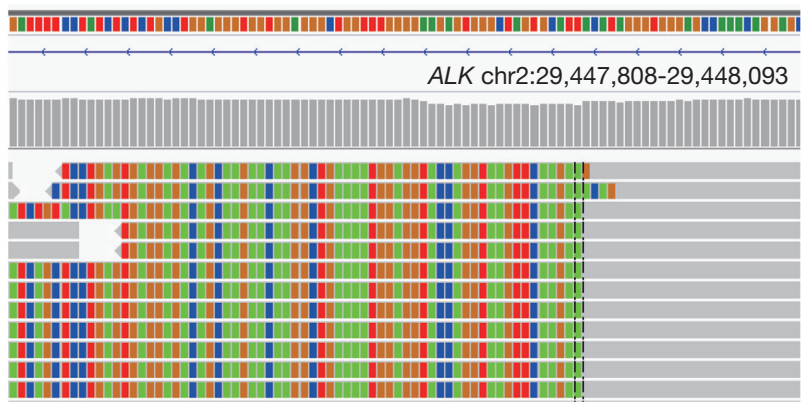

chr2

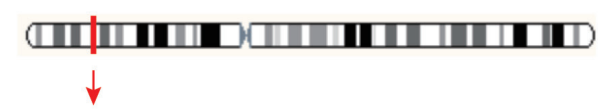

ALK (NM_004304)

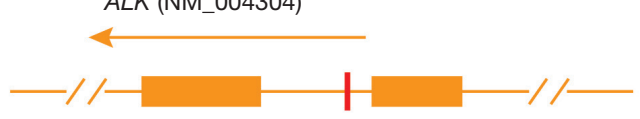

exon29-exon20

exon19-exon1
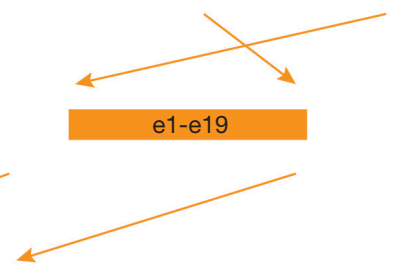

e1-e19

Figure 3 Identification and validation of the latent transforming growth factor beta-binding protein 1 (LTBP1)-anaplastic lymphoma kinase ( $A L K$ ) fusion in a NSCLC patient. (A) DNA sequencing reads of LTBP1 and ALK were visualized by the Integrative Genomics Viewer (IGV); (B) a schematic map showing the structure of the $L T B P 1-A L K$ fusion locus. NSCLC, non-small cell lung cancer.
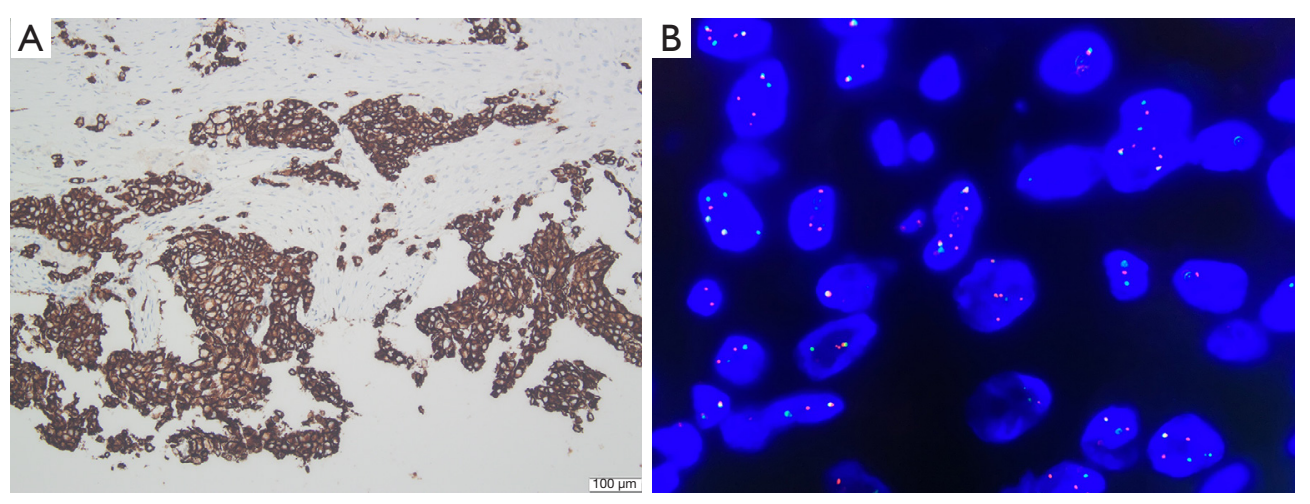

Figure 4 Molecular detection at the protein level. (A) Immunochemistry (IHC) analysis indicated the tumor sample being positive for anaplastic lymphoma kinase (ALK) (100x), using the D5F3 antibody (Ventana Medical Systems, Tucson, AZ, USA); (B) fluorescent in situ hybridization (FISH) detection of tumor tissue showed it was positive for ALK $(1,000 \times)$. 
A

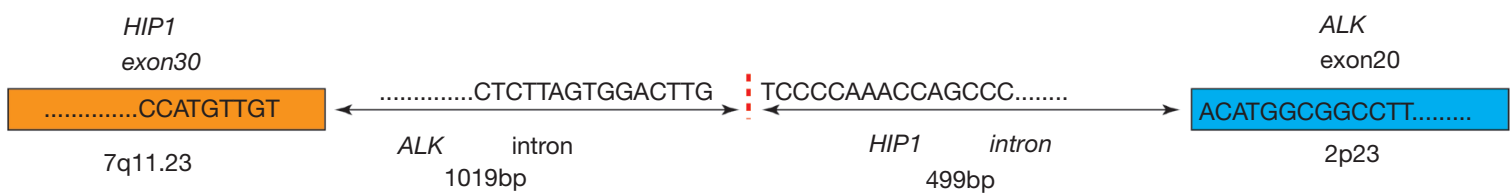

B

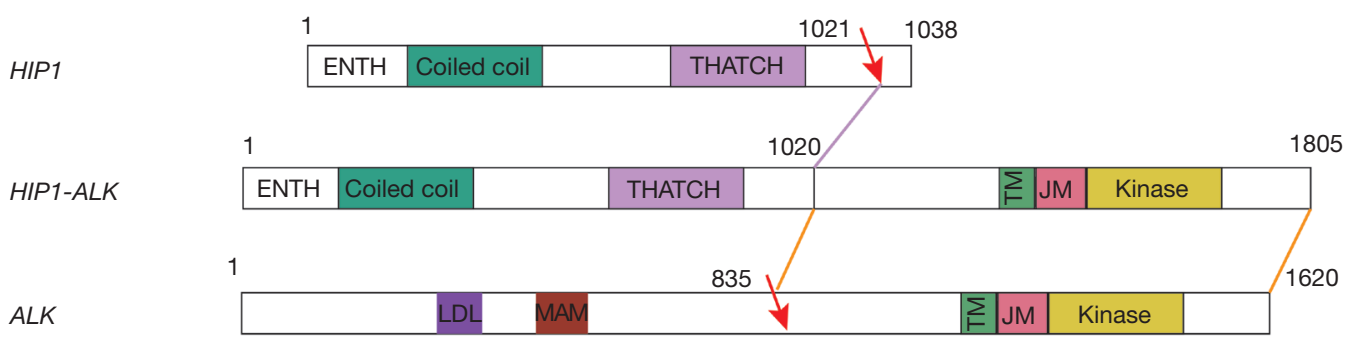

Figure 5 Illustration of the HIP1-ALK fusion at the DNA and mRNA levels. (A) Sequence analysis of the region fused between huntingtininteracting protein 1 (HIP1) and anaplastic lymphoma kinase $(A L K)$ at the genome and transcript levels. (B) Functional domain analysis of HIP1, ALK, and HIP1-ALK protein sequences.

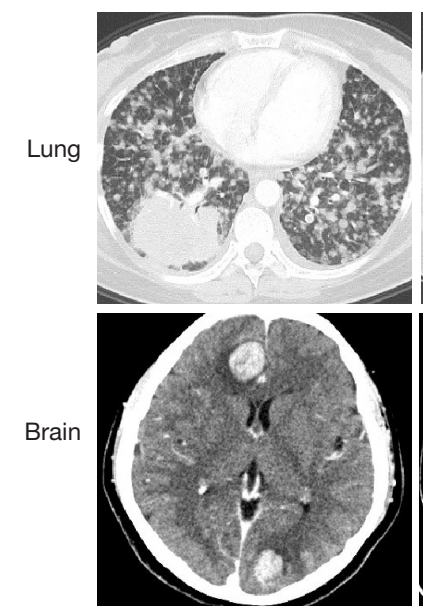

Mar. 10, 2020 Baseline
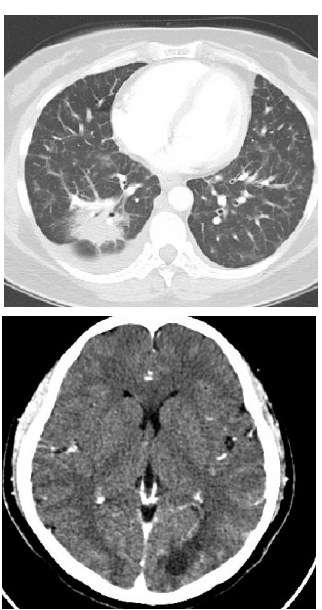

Apr. 27, 2020 I mo.
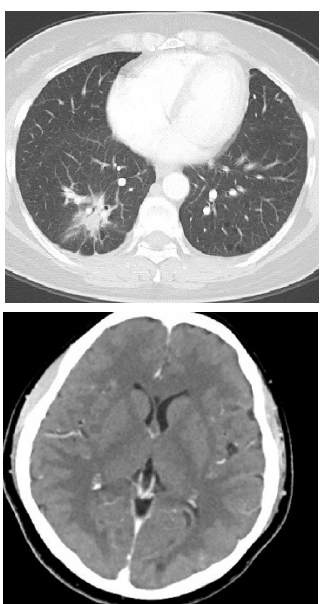

Dec. 28,2020 $9 \mathrm{mo}$.
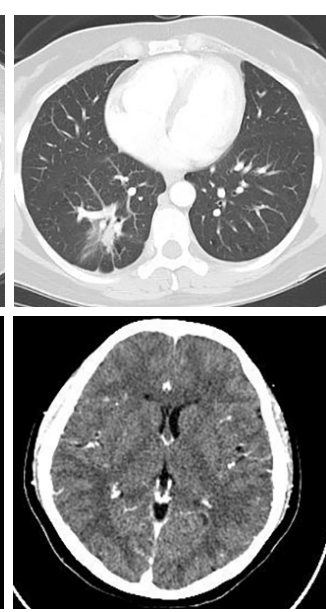

Jul.07,2021 $15 \mathrm{mo}$.
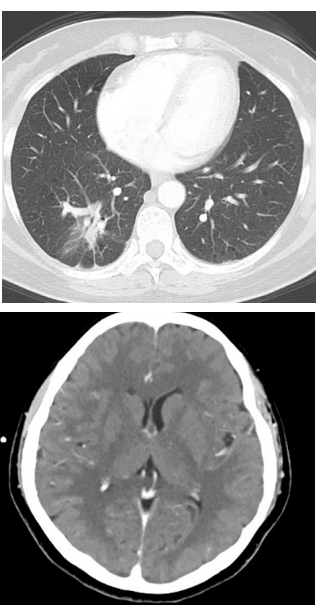

Nov. 03, 2021 $19 \mathrm{mo}$.

Figure 6 Imaging evaluation of the therapeutic effects of targeted therapy.

consent is available for review by the editorial office of this journal.

\section{International multidisciplinary team (IMDT) discussion}

\section{Discussion among physicians from Shandong Cancer Hospital and Institute}

$A L K$ fusion is known as a "diamond mutation" because of its very low mutation rate and good response to ALK-
TKIs which can considerably improve the PFS and OS of patients with $A L K+$ NSCLC. Thus, the ability to detect $A L K$ fusions is important to benefit these patients. Based on this clinical need, there has been constant innovation in molecular detection technology. In clinical application, NGS has gradually taken the place of traditional methods such as FISH and IHC. Currently, high-throughput sequencing technology has increased the chance of identifying new fusion genes that have activities similar to classic $A L K$ fusions $(19,20)$, potentially matching more 
Table 1 Catalog of previous reports of $H I P 1-A L K+$ lung cancer

\begin{tabular}{|c|c|c|c|c|c|c|c|c|c|}
\hline No. & Year & $\begin{array}{l}\text { Chromosomal } \\
\text { location }\end{array}$ & $\begin{array}{l}\text { Fusion } \\
\text { breakpoint }\end{array}$ & Response to ALK-TKI & $\begin{array}{l}\text { Tumor } \\
\text { source }\end{array}$ & $\begin{array}{l}\text { Detection } \\
\text { method }\end{array}$ & VAF & $\begin{array}{l}\mathrm{FISH} / \\
\mathrm{IHC}\end{array}$ & References \\
\hline 1 & 2014 & $7 q 11.23$ & (H28:A20) & $\begin{array}{l}\text { Not treated with ALK TKI (PDX } \\
\text { crizotinib sensitive) }\end{array}$ & Tumor & RNA NGS & NR & ND/ND & $\begin{array}{l}\text { Douglas D. Fang, et } \\
\text { al. }\end{array}$ \\
\hline 2 & 2014 & $7 q 11.23$ & (H21:A20) & PR to crizotinib & Tumor & RT-PCR & NR & $+/+$ & Mineui Hong, et al. \\
\hline 3 & 2014 & $7 q 11.23$ & (H30: A20) & PR to crizotinib \& alectinib & Tumor & DNA NGS & NR & $+/ N D$ & $\begin{array}{l}\text { Sai-Hong lgnatius } \\
\text { Ou, et al. }\end{array}$ \\
\hline 4 & 2016 & - & (H19:A20) & Not treated with ALK TKI & - & - & NR & $+/+$ & Jin Sung Jang, et al. \\
\hline 5 & 2019 & $7 q 11.23$ & (H28:A20) & PR to crizotinib (PFS $26.9 \mathrm{~m}$ ) & Tumor & $\begin{array}{l}\text { DNA NGS } \\
\text { (WES) }\end{array}$ & NR & ND/ND & $\begin{array}{l}\text { Mathilde Couëtoux } \\
\text { du Tertre, et al. }\end{array}$ \\
\hline 6 & 2020 & $7 q 11.23$ & (H22:A21) & PR to crizotinib (PFS $7.0 \mathrm{~m}$ ) & Tumor & DNA NGS & NR & ND/ND & Panwen Tian, et al. \\
\hline
\end{tabular}

+, positive. HIP1, huntingtin-interacting protein 1; ALK, anaplastic lymphoma kinase; TKI, tyrosine kinase inhibitor; NGS, next-generation sequencing; RT-PCR, reverse transcriptase polymerase chain reaction; WES, whole exome sequencing; VAF, variant frequency; FISH, fluorescent in situ hybridization; IHC, immunochemistry; NR, not reported; ND, not detected.

patients to existing drugs. NGS-based assessment for $A L K$ fusions is more accurate and comprehensive, and has the unique advantage of being able to detect unknown $A L K$ fusion partners and identify the exact breakpoints. DNA and RNA-based NGS assay should are thus both valuable in fusion detection. DNA-based NGS can identify genomics rearrangements not limited to fusion, such as amplification of the $A L K$ locus, a newly discovered truncated form that activates drivers but does not lead to fusion transcripts and proteins (21). RNA-based NGS offers a more direct approach to detecting clinically actionable fusions compared to RNA sequencing, which focuses more on exons postsplicing and may thus bypass genomic complexities (22). Future optimization of NGS panel probe design will be essential to tilling the selected intronic regions of fusion partner genes. Meanwhile, RNA and protein level assays may be critical for clarifying the function of complex $A L K$ rearrangements and better informing decisions concerning treatment in clinical practice (23).

This is the first reported case of a concurrent combination of two rare $A L K$ fusions that showed a favorable response to alectinib. It is of particular interest that $L T B P 1-A L K$ was detected at the DNA level but not expressed at the RNA level in this case. Details regarding the RNA-NGS panel from Berry Oncology used in this study are not publicly available, as the DNA and RNA panels are an in-house design, the publication of which is constrained by intellectual property rights, trade secrets, and commercial interests. The RNA-NGS used here was PCR (amplicon)-based. Since LTBP1 is not a common or established fusion partner for $A L K$, we speculate that LTBP1 was simply not included in the RNA-NGS panel of this study.

There have been 7 previous reports of HIP1-ALK+ lung cancer (24-30) (Table 1), and patients with this fusion have received mixed therapeutic effects from ALK-TKIs. Among these patients, 3 receiving first-line crizotinib treatment and 1 receiving first-line alectinib treatment achieved $\mathrm{PR}$, while 1 patient showed resistance to crizotinib but received benefit from alectinib. Of note, only 1 among the described cases had the H30:A20 fusion variant (case 3 in Table 1) that was detected in our case (Figure 2) and showed sensitivity to both crizotinib and alectinib (26). The reasons for the variable efficacy of crizotinib in patients with HIP1$A L K$ fusion and the related mechanism still need to be investigated. Although there was a single case of a patient with an H19:A20 fusion variant with resistance to crizotinib in the literature (Table 1, case 7), no HIP1-ALK case with primary alectinib resistance has been reported to date.

Two reports of lung cancer LTBP1-ALK fusion mutations exist $(31,32)$ (Table 2$)$, and both patients received firstline treatment with crizotinib and reached PR. The kinase domain of $A L K$ is located in exon 20 (4), and the tyrosine kinase domain (exon 20 of $A L K$ ) was present in these cases; however, in our case, the LTBP1-ALK occurred in ALK intron 19 (the retained portion was exon 1-19), leaving the 
Table 2 Catalog of previous reports of $L T B P 1-A L K+$ lung cancer

\begin{tabular}{|c|c|c|c|c|c|c|c|c|c|}
\hline No. & Year & $\begin{array}{l}\text { Chromosomal } \\
\text { location }\end{array}$ & $\begin{array}{l}\text { Fusion } \\
\text { breakpoint }\end{array}$ & Response to ALK-TKI & $\begin{array}{l}\text { Tumor } \\
\text { source }\end{array}$ & Detection method & VAF & $\mathrm{FISH} / \mathrm{IHC}$ & References \\
\hline 8 & 2018 & - & - & PR to crizotinib & Tumor & $\begin{array}{l}\text { RT-PCR Sanger } \\
\text { sequencing }\end{array}$ & $2.7 \%$ & $+/+$ & Cristina Aguado, et al. \\
\hline 9 & 2020 & - & (L1-30:A20-29) & PR to crizotinib & Tumor & DNA NGS & \multicolumn{2}{|c|}{$13.30 \%+/+$} & Huiwen Qian, et al. \\
\hline
\end{tabular}

+, positive. LTBP1, latent transforming growth factor beta-binding protein 1; ALK, anaplastic lymphoma kinase; TKI, tyrosine kinase inhibitor; RT-PCR, reverse transcriptase polymerase chain reaction; NGS, next-generation sequencing; VAF, variant frequency; FISH, fluorescent in situ hybridization; IHC, immunochemistry.

kinase domain behind. Even if it had been transcribed, the protein would not have contained the ALK tyrosine kinase domain. Therefore, the efficacy of alectinib in this case was only based on the HIP1-ALK fusion.

Previous studies have demonstrated that the 5' fusion partner, i.e. the gene partner and the exact fusion variant, i.e., involved exon of the 5'-partner gene, can affect ALK TKI drug sensitivity $(33,34)$. However, our understanding of the mechanisms that govern how the 5 ' partner affects the biology of the fusion and responsiveness to ALK-TKIs is still limited. Therefore, a subsequent step in research will be to identify the drug-sensitive fusions and drug-resistant fusion mutations in $A L K+$ NSCLC patients. To this end, our report enriches the knowledge of $A L K$ fusion types and broadens the clinical basis for the screening and mechanistic workup of sensitive variants.

\section{Several issues regarding the diagnosis and treatment of this patient were further discussed and are presented here}

Question 1: Why was LTBP1-ALK detected at the DNA level but not at the RNA level?

Expert opinion 1: Dr. Anna Grenda

RNA molecules undergo posttranscriptional processing that can alter the exon composition of the mature mRNA molecule. Therefore, it could be that the break/fusion site that was observed at the DNA level was cleaved/modified in such a way that the fusion partner was not present. It could be that some of the RNA molecules had a fusion variant; however, the number of fused molecules was below the detection threshold.

\section{Expert opinion 2: Dr. Marc G. Denis}

There are two possible explanations. The first one is related to the assay used. The $L T B P 1-A L K$ rearrangement at the DNA level involves exon 1-19 of the $A L K$ gene. It would be interesting to know if the RNA sequencing assay is able to detect RNA transcripts containing theses exons fused to the first 3 exons of LTBP1.

The second hypothesis is that this gene rearrangement is not transcribed or is transcribed at a low level. Transcription of this $L T B P 1-A L K$ hybrid gene depends on the LTBP1 promoter, which might be weak in lung tumor cells.

FISH analysis and DNA-based NGS assays do not indicate if the gene is transcribed. This is an important advantage of RNA sequencing and of other RNA-based approaches. Without RNA transcripts, the fusion protein is not expressed, and the targeted therapies cannot be efficient.

\section{Expert opinion 3: Dr. Petros Christopoulos}

The RNA-NGS used here was PCR (amplicon)-based, so presumably LTBP1 was simply not included in the RNANGS panel of this study. This is very likely, because $L T B P 1$ is not a common or established fusion partner for $A L K$; for example, LTBP1 is not included in the Ion AmpliSeq RNA Fusion Lung Cancer Research panel from Thermo Fisher. Unfortunately, no details are given about the RNA-NGS panel from Berry Oncology used in this study.

Question 2: What are the reasons for the different efficacy of crizotinib in patients with HIP1-ALK fusion? Expert opinion 1: Dr. Anna Grenda

NGS has resulted in the possibility of identifying new mutational variants of uncertain significance as well as new, rare fusion variants that may impact the efficacy of a molecularly targeted treatment. The identification of HIP1-ALK fusions is in line with the trend of expanding information on the biology and efficacy of anti-ALKTKI, which has not been fully explained. The different efficacy of crizotinib in patients with this type of change may result from the way these two genes fuse (i.e., where they break and join) which will ultimately determine the amino acid composition of the fusion protein and thus the affinity to the drug. The molecular background, or the coexistence of mutations in suppressor genes which are 
not directly a therapeutic target but whose dysfunctions may have an impact on a worse prognosis for patients, may be important for the effectiveness of treatment. A holistic approach to this topic through genomic, transcriptomic, and proteomic analysis can provide a lot of information regarding the differences in the effectiveness of treatment with molecularly targeted therapies.

\section{Expert opinion 2: Dr. Marc G. Denis}

Targeted therapies have been shown to be effective when a specific alteration is present in the tumor. In clinical trials, response rates are often high $(>50 \%)$, but not all patients respond to these treatments. Certain characteristics of patients and/or of their tumors may be responsible for the lack of response. This is particularly the case with mutations in other genes. For example, co-mutations in the TP53 tumor suppressor gene have been associated with a reduced response to treatment. Since the number of HIP1-ALK fusion patients is limited, it will be difficult to demonstrate which tumor characteristic is responsible for variable efficacy of ALK inhibitors.

\section{Expert opinion 3: Dr. Petros Christopoulos}

This is the subject of ongoing studies. Generally, the 5'- partner (i.e., EML4 in EML4-ALK, and HIP1 in $H I P 1-A L K)$ (I) determines how strong the oncoprotein expression will be (because this relies on the promoter of the 5 '-partner gene), and (II) causes the oligomerization and autophosphorylation of oncoprotein molecules. Both of these effects enhance the oncogenicity of the fusion protein, which can therefore differ depending on the exact fusion partner. Furthermore, several other molecular features can additionally influence the responsiveness to ALK TKI, like the presence of co-mutations, such as TP53, and the immune microenvironment. I am not aware of any published results comparing the exact biochemical properties of $A L K$ fusion oncoproteins with HIP1 vs. other 5'-partners.

Question 3: How does the 5' partner affect the biology of the fusion or responsiveness to ALK-TKIs?

Expert opinion 1: Dr. Anna Grenda

Depending on the $A L K$ fusion partner, the fusion protein may have a different degree of affinity for ALK inhibitors. Recognition, matching, and strong binding of the therapeutic molecule to the fusion protein appear to have a large impact on the efficacy of anti-ALK targeted therapy. The amino acid composition of the ALK fusion protein into which the fusion partner has contributed its sequence, may affect the spatial arrangement of the protein and thus alter the affinity and binding strength of crizotinib to the fusion protein, which may be associated with alterations in the efficacy of anti-ALK-TKI treatment. Thanks to NGS technology, new fusion partners, not previously described, can be identified, which broadens the knowledge about the biology of $A L K$ fusion and its impact on the effectiveness of targeted treatment.

\section{Expert opinion 2: Dr. Marc G. Denis}

The $5^{\prime}$ partner is involved at several levels. First, the promoter of the corresponding gene drives the transcription of the fusion. The concentration of the specific transcript (and of the corresponding protein) may thus vary. Second, the structure of the protein will be different. The amino terminal part may have an impact on the overall structure of the protein and thus on the tyrosine kinase activity.

\section{Expert opinion 3: Dr. Petros Christopoulos}

Generally, the 5'-partner (e.g., EML4 in EML4-ALK, and HIP1 in HIP1-ALK) (I) determines how strong the oncoprotein expression will be (because this relies on the promoter of the 5'-partner gene) and (II) causes the oligomerization and autophosphorylation of oncoprotein molecules. Both of these effects enhance the oncogenicity of the fusion protein. In addition, even among $A L K$ fusions with EML4 as the 5'-partner, different breakpoints can result in different biological properties. For example, it is known that V3 (E6;A20) has a higher stability and stronger interaction with the cytoskeleton than do the longer EML4$A L K$ variants V1 (E13;A20) and V2 (E20;A20), which results in worse prognosis for V3-driven tumors. However, I am not aware of any published data comparing the strength of expression, strength of oligomerization, protein stability, and ability to interact with the cytoskeleton for ALK fusion oncoproteins with HIP1 vs. other 5'-partners.

\section{Acknowledgments}

We thank Xiaoxing Su and Yan Lei from Berry Oncology Corporation for Bioinformatics technology support.

Funding: This work was supported by a grant from the Shandong Key Research and Development Program (No. 2019GSF108251).

\section{Footnote}

Reporting Checklist: The authors have completed the CARE reporting checklist Available at https://tlcr.amegroups.com/ article/view/10.21037/tlcr-21-1039/rc 
Conflicts of Interest: All authors have completed the ICMJE uniform disclosure form (available at https://tlcr.amegroups. com/article/view/10.21037/tlcr-21-1039/coif). All authors report bioinformatics technology support from Xiaoxing Su and Yan Lei who are from Berry Oncology Corporation. YL and QG report funding from the Shandong Key Research and Development Program (No. 2019GSF108251). PC has received research funding from AstraZeneca, Novartis, Roche, and Takeda, speaker's honoraria from AstraZeneca, Novartis, Roche, Takeda, support for attending meetings from AstraZeneca, Eli Lilly, Novartis, Takeda, and personal fees for participating to advisory boards from Boehringer Ingelheim, Chugai, Pfizer and Roche, all outside the submitted work. The authors have no other conflicts of interest to declare.

Ethical Statement: The authors are accountable for all aspects of the work in ensuring that questions related to the accuracy or integrity of any part of the work are appropriately investigated and resolved. All procedures performed in this study were in accordance with the ethical standards of the institutional and/or national research committee(s) and with the Helsinki Declaration (as revised in 2013). Written informed consent was obtained from the patient for publication of this case report and accompanying images. A copy of the written consent is available for review by the editorial office of this journal.

Open Access Statement: This is an Open Access article distributed in accordance with the Creative Commons Attribution-NonCommercial-NoDerivs 4.0 International License (CC BY-NC-ND 4.0), which permits the noncommercial replication and distribution of the article with the strict proviso that no changes or edits are made and the original work is properly cited (including links to both the formal publication through the relevant DOI and the license). See: https://creativecommons.org/licenses/by-nc-nd/4.0/.

\section{References}

1. Kwak EL, Bang YJ, Camidge DR, et al. Anaplastic lymphoma kinase inhibition in non-small-cell lung cancer. N Engl J Med 2010;363:1693-703.

2. Devarakonda S, Morgensztern D, Govindan R. Genomic alterations in lung adenocarcinoma. Lancet Oncol 2015;16:e342-51.

3. Addeo A, Tabbò F, Robinson T, et al. Precision medicine in ALK rearranged NSCLC: A rapidly evolving scenario.
Crit Rev Oncol Hematol 2018;122:150-6.

4. Duyster J, Bai RY, Morris SW. Translocations involving anaplastic lymphoma kinase (ALK). Oncogene 2001;20:5623-37.

5. Hallberg B, Palmer RH. Mechanistic insight into ALK receptor tyrosine kinase in human cancer biology. Nat Rev Cancer 2013;13:685-700.

6. Wu J, Savooji J, Liu D. Second- and third-generation ALK inhibitors for non-small cell lung cancer. J Hematol Oncol 2016;9:19.

7. Morris $\mathrm{SW}$, Kirstein $\mathrm{MN}$, et al. Fusion of a kinase gene, ALK, to a nucleolar protein gene, NPM, in nonHodgkins-lymphoma. Science 1994;263:1281-4. Erratum in: Science 1995;267:316-7.

8. Soda M, Choi YL, Enomoto M, et al. Identification of the transforming EML4-ALK fusion gene in non-small-cell lung cancer. Nature 2007;448:561-6.

9. Inamura K, Takeuchi K, Togashi Y, et al. EML4-ALK fusion is linked to histological characteristics in a subset of lung cancers. J Thorac Oncol 2008;3:13-7.

10. Noh KW, Lee MS, Lee SE, et al. Molecular breakdown: a comprehensive view of anaplastic lymphoma kinase (ALK)-rearranged non-small cell lung cancer. J Pathol 2017;243:307-19.

11. von Laffert M, Warth A, Penzel R, et al. Multicenter immunohistochemical ALK-testing of non-small-cell lung cancer shows high concordance after harmonization of techniques and interpretation criteria. J Thorac Oncol 2014;9:1685-92.

12. Chiarle R, Voena C, Ambrogio C, et al. The anaplastic lymphoma kinase in the pathogenesis of cancer. Nat Rev Cancer 2008;8:11-23.

13. Guan J, Umapathy G, Yamazaki Y, et al. FAM150A and FAM150B are activating ligands for anaplastic lymphoma kinase. Elife 2015;4:e09811.

14. Peters S, Camidge DR, Shaw AT, et al. Alectinib versus Crizotinib in Untreated ALK-Positive Non-Small-Cell Lung Cancer. N Engl J Med 2017;377:829-38.

15. Hida T, Nokihara H, Kondo M, et al. Alectinib versus crizotinib in patients with ALK-positive non-small-cell lung cancer (J-ALEX): an open-label, randomised phase 3 trial. Lancet 2017;390:29-39.

16. Larkins E, Blumenthal GM, Chen H, et al. FDA Approval: Alectinib for the Treatment of Metastatic, ALK-Positive Non-Small Cell Lung Cancer Following Crizotinib. Clin Cancer Res 2016;22:5171-6.

17. Ross JS, Ali SM, Fasan O, et al. ALK Fusions in a Wide Variety of Tumor Types Respond to Anti-ALK Targeted 
Therapy. Oncologist 2017;22:1444-50.

18. Ou SI, Zhu VW, Nagasaka M. Catalog of 5' Fusion Partners in ALK-positive NSCLC Circa 2020. JTO Clin Res Rep 2020;1:100015.

19. Lipson D, Capelletti M, Yelensky R, et al. Identification of new ALK and RET gene fusions from colorectal and lung cancer biopsies. Nat Med 2012;18:382-4.

20. Peled N, Palmer G, Hirsch FR, et al. Next-generation sequencing identifies and immunohistochemistry confirms a novel crizotinib-sensitive ALK rearrangement in a patient with metastatic non-small-cell lung cancer. J Thorac Oncol 2012;7:e14-e16.

21. Cazes A, Louis-Brennetot C, Mazot P, et al. Characterization of rearrangements involving the ALK gene reveals a novel truncated form associated with tumor aggressiveness in neuroblastoma. Cancer Res 2013;73:195-204.

22. Benayed R, Offin M, Mullaney K, et al. High Yield of RNA Sequencing for Targetable Kinase Fusions in Lung Adenocarcinomas with No Mitogenic Driver Alteration Detected by DNA Sequencing and Low Tumor Mutation Burden. Clin Cancer Res 2019;25:4712-22.

23. Xia P, Zhang L, Li P, et al. Molecular characteristics and clinical outcomes of complex ALK rearrangements identified by next-generation sequencing in non-small cell lung cancers. J Transl Med 2021;19:308.

24. Fang DD, Zhang B, Gu Q, et al. HIP1-ALK, a novel ALK fusion variant that responds to crizotinib. J Thorac Oncol 2014;9:285-94.

25. Hong M, Kim RN, Song JY, et al. HIP1-ALK, a novel fusion protein identified in lung adenocarcinoma. J Thorac Oncol 2014;9:419-22.

26. Ou SH, Klempner SJ, Greenbowe JR, et al. Identification of a novel HIP1-ALK fusion variant in Non-Small-Cell Lung Cancer (NSCLC) and discovery of ALK I1171 (I1171N/S) mutations in two ALK-rearranged NSCLC

Cite this article as: Li Y, Duan P, Guan Y, Chen Q, Grenda A, Christopoulos P, Denis MG, Guo Q. High efficacy of alectinib in a patient with advanced lung adenocarcinoma with 2 rare $A L K$ fusion sites: a case report. Transl Lung Cancer Res 2022;11(1):100-110. doi: 10.21037/tlcr-21-1039 patients with resistance to Alectinib. J Thorac Oncol 2014;9:1821-5.

27. Jang JS, Wang X, Vedell PT, et al. Custom Gene Capture and Next-Generation Sequencing to Resolve Discordant ALK Status by FISH and IHC in Lung Adenocarcinoma. J Thorac Oncol 2016;11:1891-900.

28. Couëtoux du Tertre M, Marques M, Tremblay L, et al. Analysis of the Genomic Landscape in ALK+ NSCLC Patients Identifies Novel Aberrations Associated with Clinical Outcomes. Mol Cancer Ther 2019;18:1628-36.

29. Tian P, Liu Y, Zeng H, et al. Unique molecular features and clinical outcomes in young patients with non-small cell lung cancer harboring ALK fusion genes. J Cancer Res Clin Oncol 2020;146:935-44.

30. Li M, Tang Q, Chen S, et al. A novel HIP1-ALK fusion variant in lung adenocarcinoma showing resistance to Crizotinib. Lung Cancer 2021;151:98-100.

31. Aguado C, Gil MD, Yeste Z, et al. Response to crizotinib in a non-small-cell lung cancer patient harboring an EML4-ALK fusion with an atypical LTBP1 insertion. Onco Targets Ther 2018;11:1117-20.

32. Qian H, Li J, Zou L, et al. LTBP1-ALK: A novel fusion identified in malignant pleural effusions from a patient with advanced lung adenocarcinoma. Lung Cancer 2020;144:93-7.

33. Childress MA, Himmelberg SM, Chen H, et al. ALK Fusion Partners Impact Response to ALK Inhibition: Differential Effects on Sensitivity, Cellular Phenotypes, and Biochemical Properties. Mol Cancer Res 2018;16:1724-36.

34. Christopoulos P, Kirchner M, Endris V, et al. EML4ALK V3, treatment resistance, and survival: refining the diagnosis of ALK+ NSCLC. J Thorac Dis 2018;10:S1989-91.

(English Language Editor: J. Gray) 